\title{
Comparison of Amsel's Criteria, Nugent Score and Culture for the Diagnosis of Bacterial Vaginosis
}

\section{ABSTRACT}

Introduction: Bacterial vaginosis is defined as an alteration in the vaginal microbiota that presents as foul smelling vaginal discharge. This syndrome not only leads to various adverse outcomes of pregnancy, but also increases the chances of acquisition of Human immunodeficiency virus by two fold.

Aims: To compare Amsel's criteria, Nugent score and culture for the diagnosis of bacterial vaginosis.

Materials and Methods: A cross sectional comparative study has been conducted in the Department of Microbiology. Total number of subjects included in the study was 130 . Two high vaginal swabs were collected from each subject during speculum examination. Amsel's criteria, Nugent score and culture were performed.

Statistical Analysis: Results were analysed by Chi-square test using IBM-SPSS Statistics-22 statistical package.

Result: Amsel's criteria detected $35.38 \%$, Nugent score identified $14.61 \%$ and culture found $16.15 \%$ of subjects as having bacterial vaginosis.

Conclusion: Amsel's criteria are useful as a bed side test, Nugent score is the appropriate diagnostic test and culture is to be reserved and performed in treatment failure cases.

\section{INTRODUCTION}

Bacterial vaginosis is a polymicrobial syndrome characterized by replacement of normal vaginal lactobacilli by anaerobic bacteria [1]. The etiological agents of bacterial vaginosis is a long list comprising of Gardnerella vaginalis, Mobiluncus species, Prevotella species, Mycoplasmahominis, Bacteroides ureolyticus, Porphyromonas species, Peptostreptococcus species, Clostridium species and Fusobacterium species $[2,3]$. Various methods available for the diagnosis of bacterial vaginosis are Amsel's criteria, Nugent score, Hays/Ison system, Schimdt's scoring system, Spiegel's criteria, anaerobic culture, gas liquid chromatograpy, sialidase activity and DNA probes for Gardnerella vaginalis. In this study, we compared Amsel's criteria, Nugent score and culture for the diagnosis of bacterial vaginosis.

\section{MATERIALS AND METHODS}

A cross sectional comparative study has been conducted in the Department of Microbiology, Stanley Medical College in association with Department of Sexually Transmitted Diseases, Government Stanley hospital, Chennai during a one year period from January to December 2012. A total of 130 sexually active women who presented with complaints of vaginal discharge were the study subjects. Women in menstruation or with genital prolapse, with history of antibiotic intake within two weeks prior to the visit were excluded from the study. Ethical and research clearance for the study was obtained from the Institutional Ethical Committee and written informed consent was obtained from each patient before enrolment into the study.

The procedure was explained to the patient and after wearing sterile gloves, speculum was inserted into the vagina. The nature, colour, amount and consistency of the discharge were noted. Two sterile cotton swabs were inserted into the vagina and the discharge was collected from the posterior and lateral fornix. Discharge from speculum was subjected to saline mount, $\mathrm{pH}$ determination and whiff test. Swab one was used for preparing smear for Nugent score, swab two was inoculated into blood agar and human bilayer tween blood agar for culture of aerobic and anaerobic organisms.

Amsel's criteria [4,5]: i) Presence of homogenous vaginal discharge, ii) $\mathrm{pH} \geq 4.5$, [Table/Fig-1] iii) Presence of amine odour which is demonstrated by adding $10 \% \mathrm{KOH}$ to the discharge, iv) Presence of clue cell (20\%) in the saline mount. Presence of three out of four among the above mentioned criteria was considered as significant for diagnosis of bacterial vaginosis. Absence of lactobacilli is an additional criterion.

Nugent score [6,7]: Clean grease free slide was taken and smear was prepared by rolling the swab on the slide in one direction. The smear was air dried and gram stain was performed. Scoring was done by observing the smear under oil immersion [Table/Fig-2 and 3].

Culture: After inoculation, blood agar was incubated aerobically and human blood bilayer tween agar was incubated in anaerobic atmosphere using Mclntosh-Fildes jar at $37^{\circ} \mathrm{C}$ for 48 hrs. 


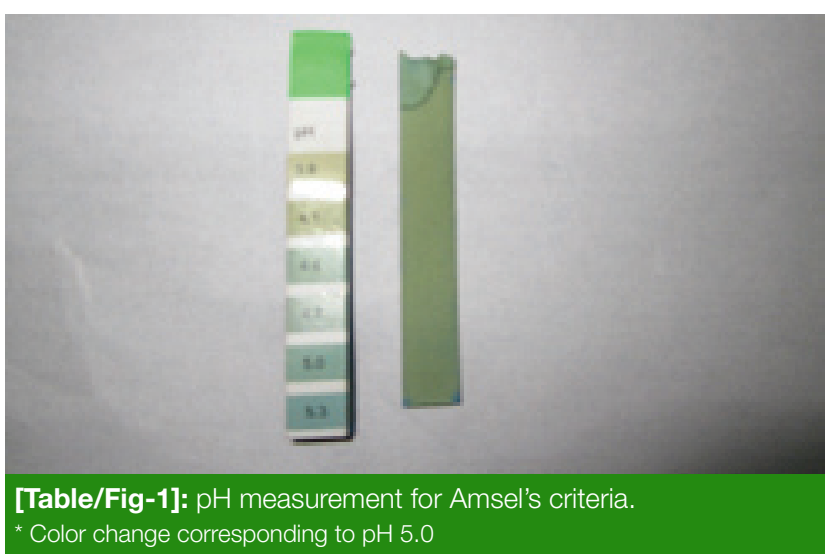

\begin{tabular}{|c|c|c|}
\hline Organism Morphotype & $\begin{array}{l}\text { Number/oil } \\
\text { immersion field }\end{array}$ & Score \\
\hline \multirow{5}{*}{$\begin{array}{l}\text { Lactobacillus - like } \\
\text { (parallel sided, gram } \\
\text { positive rods) }\end{array}$} & $>30$ & 0 \\
\hline & $5-30$ & 1 \\
\hline & $1-4$ & 2 \\
\hline & $<1$ & 3 \\
\hline & 0 & 4 \\
\hline \multirow{3}{*}{$\begin{array}{l}\text { Mobiluncus - like } \\
\text { (curved, gram negative } \\
\text { rods) }\end{array}$} & $>5$ & 2 \\
\hline & $<1-4$ & 1 \\
\hline & 0 & 0 \\
\hline \multirow{5}{*}{$\begin{array}{l}\text { Gardnerella/bacteroides } \\
\text { - like (tiny, gram variable } \\
\text { coccobacilli and } \\
\text { pleomorphic rods with } \\
\text { vacuoles) }\end{array}$} & $>30$ & 4 \\
\hline & $5-30$ & 3 \\
\hline & $1-4$ & 2 \\
\hline & $<1$ & 1 \\
\hline & 0 & 0 \\
\hline
\end{tabular}

[Table/Fig-2]: Nugent scoring of Gram stained smear for bacterial vaginosis.

Total score:- 0-3 Normal; 4-6 Intermediate, repeat test later; 7-10

Bacterial vaginosis.

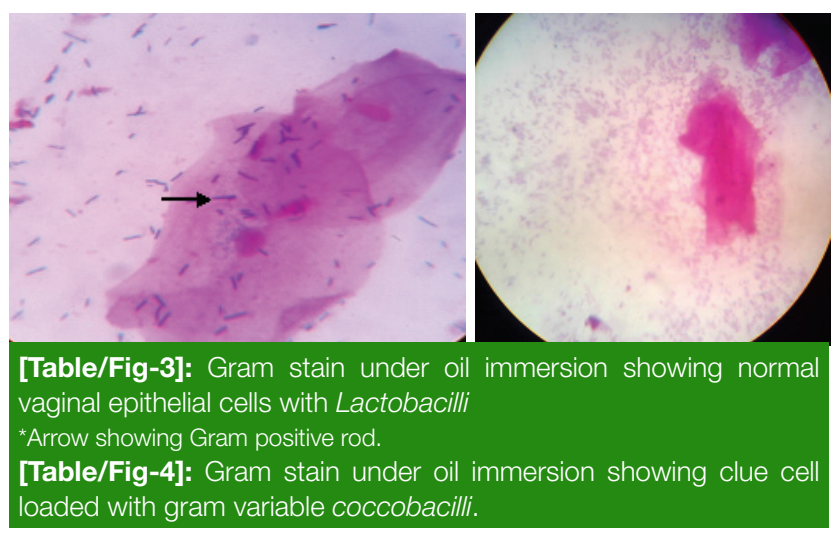

1. Aerobes were identified based on the colony morphology, gram stain and biochemical reactions.

2. Gardnerella vaginalis [8] was identified by observing for tiny translucent beta hemolytic colonies which were catalase and oxidase negative, gram negative/variable coccobacilli [Table/Fig-4]. Identification discs like metronidazole 50 $\mu \mathrm{g}$, bacitracin $5 \mathrm{IU}$ and sodium polyanethol sulphonate (SPS) disc $100 \mu \mathrm{g}$ prepared by adding $20 \mu \mathrm{l}$ of $5 \%$ SPS solution to sterile Whatman No.1 filter paper disc were used [9].

3. Obligate anaerobes [10] were identified based on colony morphology, beta hemolysis, pigment production, swarming, aerotolerance test and gram stain findings. Identification discs used were vancomycin $5 \mu \mathrm{g}$, colistin $10 \mu \mathrm{g}$ and kanamycin $1 \mathrm{mg}$.

\section{RESULTS}

The total number of females participated in our study was 130. Statistical analysis was done by Chi-square test using IBMSPSS Statistics-22 statistical package. Results of Amsel's criteria, Nugent score and culture were shown individually in [Table/Fig-5-7] respectively. According to Amsel's criteria, $35.38 \%$ of females were considered as having bacterial vaginosis. By Nugent scoring, bacterial vaginosis was diagnosed in $14.61 \%$ of women and culture diagnosed $16.15 \%$ of females as suffering from this polymicrobial syndrome. Result of comparison of all three methods was shown in [Table/Fig-8]. Though the three tests showed varying ability to diagnose bacterial vaginosis, the difference was not found to be statistically significant ( $p$-value $>0.05$ ).

\section{DISCUSSION}

Bacterial vaginosis is the commonest infection among women visiting reproductive health clinic. It is a simple to treat infection but can lead on to complications like miscarriage, pre term delivery, low birth weight baby, premature rupture of membranes, chorioamnionitis, postpartum endometritis, vaginal cuff cellulitis and pelvic inflammatory disease. Among the various methods available for diagnosis of bacterial vaginosis, Amsel's criteria is easy to perform and often used by clinicians for establishing clinical diagnosis. Nugent score is considered as the gold standard method and culture is a specific method where etiological agent is isolated but has its own disadvantages like time, cost and labor constraints.

In our study, the subjects belonged to 15-49 years of age. Among them, more than half of women fell in the decade of 30-39 years. This age group observation was comparable with the study by Anorlu et al., [11] where commonest age decade found was $31.1 \pm 6.9$ years. The reason for predominance of 30-39 years could be due to increased frequency of sexual activity in this decade compared to extremes in reproductive age group like late teenage and near menopausal age. About one third of women in our study were illiterate and belonged to low socio economic group. The positives detected in our study comprised more of illiterate females. This finding emphasizes that education and socio economic status of female plays vital role in knowledge regarding vaginal hygiene, adoption of protective measures and to overcome the social stigma in treatment seeking behavior. 
In the present study, Amsel's criteria diagnosed one third of females as having bacterial vaginosis and two thirds as normal vaginal discharge [Table/Fig-5]. This is similar to a study done by Aggarwal et al., [2] where Amsel's criteria were significant in $40 \%$ of subjects.

Nugent score categorized nearly half of the subjects (52.30\%) as having normal flora, 33.07\% as having intermediate flora and $14.61 \%$ as bacterial vaginosis [Table/Fig-6]. A study conducted by Madhivanan et al., [12] showed $65.4 \%$ had normal flora, $15.4 \%$ had intermediate flora and $19.1 \%$ had bacterial vaginosis whose proportion of three categories were comparable with the results of our study.

About $16.15 \%$ of samples grew etiological agents in our study [Table/Fig-7] which correlates well with the study by Rao et al., [3] where culture positivity was $17.42 \%$.

In our study, among the three methods, Amsel's criteria identified more positives than other two methods. Detection of positivity by Amsel's criteria was more than culture followed by Nugent scoring [Table/Fig-8]. A study by Krohn et al., [13] showed difference in the order of positives with the same three methods where culture detected more positives followed by Amsel's criteria and Nugent score. This is one among the few studies where culture positivity out numbered the positives

\begin{tabular}{|c|c|c|}
\hline Amsel's criteria & Number of females & $\%$ \\
\hline$\geq 3$ & 46 & 35.38 \\
\hline$<3$ & 84 & 62.22 \\
\hline Total & 130 & 100 \\
\hline
\end{tabular}

\begin{tabular}{|c|c|c|}
\hline Nugent score & Number of females & $\%$ \\
\hline$<4$ & 68 & 52.30 \\
\hline $4-6$ & 43 & 33.07 \\
\hline$\geq 7$ & 19 & 14.61 \\
\hline Total & 130 & 100 \\
\hline
\end{tabular}

\begin{tabular}{|c|c|c|}
\hline Culture & Number of females & $\%$ \\
\hline Positive & 21 & 16.15 \\
\hline Negative & 109 & 83.89 \\
\hline Total & 130 & 100 \\
\hline
\end{tabular}

\begin{tabular}{|l|c|c|c|c|}
\hline $\begin{array}{c}\text { Test } \\
\text { performed } \\
(\mathrm{n}=130)\end{array}$ & Amsel & Nugent & Culture & $\begin{array}{c}\text { Chi } \\
\text { square } \\
\text { value }\end{array}$ \\
\hline $\begin{array}{l}\text { Number of } \\
\text { positives }\end{array}$ & 46 & 19 & 21 & 0.083 \\
\cline { 1 - 4 } $\begin{array}{l}\text { \% of } \\
\text { positives }\end{array}$ & 35.38 & 14.61 & 16.15 & $(\mathrm{p}>0.05)$ \\
\cline { 1 - 3 }
\end{tabular}

[Table/Fig-8]: Comparison of positivity by Amsel's criteria, Nugent score and culture.

National Journal of Laboratory Medicine. 2016 Jan, Vol 5(1): 37-40 by other two methods. Initial difficulties faced in isolation of anaerobes could be the reason for the lower percentage of culture positivity in our study. Another study by Udayalaxmi et al., [14] which involved comparison of Amsel, Spiegel's criteria and culture with Nugent as gold standard showed culture as the least sensitive method.

The highest and lowest percentage of positivity by Amsel's criteria and Nugent score can be due to low and high specific nature of the two tests. Though culture has its own disadvantages, it has its role when treatment failure occurs, as in co-infections or resistant isolates.

\section{LIMITATIONS}

Limitations of the study are follow-up was not done in the patients after providing specific treatment. Since there is controversy regarding the role of sexual activity in bacterial vaginosis, contact tracing was not planned. Antibiotic sensitivity test was not performed for anaerobic isolates because of the difficulties faced in maintaining the isolates while planning to perform the test in batches.

\section{CONCLUSION}

Amsel's criteria can be used in resource poor settings, with care to rule out false positives. Nugent score is specific but needs microbiology expertise and culture has its role in treatment failure cases.

\section{REFERENCES}

[1] Sobel JD. Bacterial vaginosis. Annu Rev Med. 2000;51:34956.

[2] Aggarwal A, Devi P, Jain R. Anaerobes in bacterial vaginosis. Indian J Med Microbiol. 2003;21:124-26.

[3] Rao PS, Devi S, Shriyan A, Rajaram M, Jagdishchandra K. Diagnosis of bacterial vaginosis in rural setup: comparision of clinical algorithm, smear scoring and culture by semiquantitative technique. Indian J Med Microbiol. 2004;22:47-50.

[4] Amsel R, Totten PA, Spiegel CA, Chen KC, Eschenbach D, Holmes KK. Nonspecific vaginitis. Diagnostic criteria and microbial and epidemiologic associations. Am J Med. 1983;74:14-22.

[5] Dadhwal V, Hariprasad R, Mittal S, Kapil A. Prevalence of bacterial vaginosis in pregnant women and predictive value of clinical diagnosis. Arch Gynecol Obstet. 2010;281:101-04.

[6] Nugent RP, Krohn MA, Hiller SL. Reliability of diagnosing bacterial vaginosis is improved by a standardized method of Gram stain interpretation. J Clin Microbiol. 1991;29:297-301.

[7] Mohanty S, Sood S, Kapil A, Mittal S. Interobserver variation in the interpretation of Nugent scoring method for diagnosis of bacterial vaginosis. Indian J Med Res. 2010;131:88-91.

[8] Shaw EC, Forsyth ME, Bowie WR, Black WA. Rapid presumptive identification of Gardnerella vaginalis (Haemophilus vaginalis) from human blood agar media. J clin Microibiol. 1981;108-10.

[9] Reimer LG, Reller B. Use of a sodium polyanetholsulfonate disc for the identification of Gardnerella vaginalis. J Clin Microbiol. 1985; 146-49.

[10] Set R, Sequeira L, Angadi SA, Koppikar GV. Prevalence of anaerobic bacteria in pyogenic infections. Indian $J$ Med Microbiol. 1997;15:121-22. 
[11] Anorlu R, Imosemi D, Odunukwe N, Abudu O, Otuonye M. Prevalence of HIV among women with vaginal discharge in gynaecological clinic. J Natl Med Assoc. 2004;96:367-71.

[12] Madhivanan P, Krupp K, Chandrasekaran V, Karat C, Arun A, Cohen $\mathrm{CR}$ et al. Prevalence and correlates of bacterial vaginosis among young women of reproductive age in Mysore, India. Indian J Med Microbiol. 2008;26:132.
[13] Krohn MA, Hiller SL, Eschenbach DA. Comparison of methods for diagnosing bacterial vaginosis among pregnant women. $J$ Clin Microbiol. 1989;1266-71.

[14] Udayalaxmi J, Bhat G, Kottigade S, Shenoy S. Comparison of the methods of diagnosis of bacterial vaginosis. J Clin Diagn Res. 2011;5:498-501.

\section{AUTHOR(S):}

1. Dr. Swapna Muthusamy

2. Dr. Selvi Elangovan

\section{PARTICULARS OF CONTRIBUTORS:}

1. Assistant Professor, Department of Microbiology Sri Venkateshwaraa Medical College Hospital and Research Centre, Puducherry, India.

2. Professor and Head, Department of Microbiology, Stanley Medical College, Chennai, Tamil Nadu, India.

\section{NAME, ADDRESS, E-MAIL ID OF THE CORRESPONDING AUTHOR:}

Dr. Swapna Muthusamy,

Assistant Professor, Department of Microbiology, Sri Venkateshwaraa Medical College Hospital and Research Centre, Puducherry-605102, India.

E-mail: swapnamuthuswamy@gmail.com

FINANCIAL OR OTHER COMPETING INTERESTS: None. 